\title{
Prostatic abscess: A systematic review of current diagnostic methods, treatment modalities and outcomes
}

\author{
Hasan Khudhur ${ }^{1}$ (D), Oliver Brunckhorst ${ }^{2}$ (D), Gordon Muir ${ }^{1}$ (D), Rozh Jalil ${ }^{1}$ (D), Azhar Khan ${ }^{1}$ (D), Kamran Ahmed ${ }^{1,2}$ (D)
}

Cite this article as: Khudhur H, Brunckhorst O, Muir G, Jalil R, Khan A, Ahmed K. Prostatic abscess: A systematic review of current diagnostic methods, treatment modalities and outcomes. Turk J Urol 2020; 46(4): 262-73.

ORCID iDs of the authors:

H.K. 0000-0002-8774-5499;

O.B. 0000-0002-2073-922X:

G.M. 0000-0003-2248-0749;

R.J. 0000-0002-6930-1210;

A.K. 0000-0002-2798-1115;

K.A. $0000-0002-5135-9211$

'Department of Urology, King's College Hospital, London, UK

${ }^{2}$ MRC Centre for

Transplantation, Guy's Hospital Campus, King's

College London, King's Health

Partners, London, UK

Submitted:

18.02.2020

Accepted:

26.04.2020

Available Online Date:

27.05.2020

Corresponding Author:

Kamran Ahmed

E-mail:

kamran.ahmed@kcl.ac.uk

(C) Copyright 2020 by Turkish

Association of Urology

Available online at

www.turkishjournalofurology.com

\begin{abstract}
Objective: Prostatic abscesses (PAs) are an uncommon urologic presentation with widely varying approaches in their diagnoses and management. This study, therefore, aims to systematically review the literature of PAs to identify common clinical presentations, evaluate currently utilized diagnostic and treatment modalities, and assess their outcomes.
\end{abstract}

Material and methods: A systematic review of the literature was performed using the MEDLINE and EMBASE databases, from January 1968 to June 2019. Outcome measures extracted from identified articles included age, the underlying disease, identified pathogens, diagnostic tool utilized, treatment used, and various subsequent clinical outcomes.

Results: The literature search yielded 683 articles, with a final twelve included in the review, representing a total of 210 patients. Transrectal ultrasonography (TRUS) was the most commonly used imaging tool used to identify PAs in all twelve studies. The PAs were treated with conservative antibiotic treatment in seven studies. Transurethral resection of the prostatic abscess (TURP) was utilized in eight studies with an average abscess size of $3.87 \mathrm{~cm}(3.0-4.0 \mathrm{~cm})$ and with an average hospital stay of 10.22 days in those undergoing TURP. Transperineal aspiration was seen in five studies and offered a less invasive treatment modality. Finally, TRUS-guided needle aspiration was seen in seven studies with an average hospital stay of 23.25 days. This was the longest of any identified modalities with an additional high rate of abscess recurrence.

Conclusion: Diagnosis and treatment practices of PAs remain widely varied in the literature due to a lack of clear guidelines. Based on the current evidence, we provide recommendations of treatment based on abscess size, patient age, and clinical condition. While smaller abscesses may be suited to antibiotic or TRUS-guided aspiration, transurethral approaches should be considered for larger and more complex abscesses. However, the current evidence remains poor with further research required to determine the optimum treatment modalities for patients.

Keywords: Abscess; drainage; prostate; prostatic diseases.

\section{Introduction}

Prostatic abscesses (PAs) remain an uncommon urological condition. However, they are an important diagnostic differential in developing countries and high-risk patients, such as patients with diabetes, cirrhosis, immunodeficiency, and those undergoing hemodialysis. ${ }^{[1]}$ PAs result from the focal accumulation of pus within the prostate gland, historically caused by Neisseria gonorrhea, Staphylococcus aureus, and Mycobacterium tuberculosis. However, more recently, gram- negative bacteria, such as Escherichia coli, are becoming an increasingly common causative species, often predominantly due to overt urinary tract infection seen during a patient's presentation. ${ }^{[2]}$

The increasing development of imaging modalities available has facilitated diagnosis, however, they still rely on a clinical suspicion to be utilized for diagnosis and current practice of which modality to use remains inconsistent. [3] Furthermore, there is still a large variety of treatment methods once 
identified, compounded by the increasing options available, including minimally invasive approaches. ${ }^{[4-6]}$

This large variety of diagnostic and therapeutic practice can be largely attributed to the lack of common evidence seen in PAs. This is reflected by the current lack of guidelines on the subject area. With this in mind, this systematic review of the literature aims to:

1. Identify common clinical presenting signs and symptoms of patients with PAs.

2. Assess the current diagnostic methods for evaluating PAs.

3. Evaluate and compare the effectiveness of different treatment approaches for PAs.

\section{Material and methods}

This systematic review was performed following guidelines defined in the Preferred Reporting Items of Systematic Reviews and Meta-Analysis (PRISMA) statement. ${ }^{[7]}$

\section{Study eligibility criteria}

Original research articles describing the diagnosis and treatment of patients with PAs were included in this review. Study types included were observational or interventional studies that utilized a prospective or retrospective design. This included cohort studies, case-control studies, and case series. Exclusion criteria were studies with fewer than four patients ( $\mathrm{n}=4)$, animal studies $(\mathrm{n}=8)$, case reports $(n=14)$, review articles (1), those including children less than 18 years $(\mathrm{n}=2)$, or articles unavailable in the English language. Furthermore, studies describing patients with prostatitis complicated by generalized peritonitis $(n=12)$ were also excluded from the review and have been focused on PAs cases.

\section{Main Points:}

- The most common diagnostic imaging modality identified was transrectal ultrasonography, however CT or MRI were an often-utilised adjunct for further characterisation of the abscess.

- Medical management alone with prolonged antibiotic administration was often successfully administered in smaller abscess cavities of less than $2 \mathrm{~cm}$.

- Transrectal or transperineal aspiration of larger cavities offered a less invasive management approach, however, carried a risk of inadequate treatment or recurrence.

- Surgical transurethral drainage through transurethral resection of the prostatic abscess or transurethral deroofing of the abscess was utilised in more complex abscesses and those who were clinically unwell.

- Large variability remains in diagnostic or therapeutic approaches in prostatic abscesses; higher quality evidence is required to better guide management and for the formulation of standardised guidelines

\section{Information sources and search}

Electronic databases, including MEDLINE (via PubMed) and EMBASE were systematically searched for research articles over the last 50 years (January 1968-June 2019). A combination of MeSH and key terms were utilized to search the PubMed database including "(prostate OR prostatic)" AND "(abscess* OR pus)" AND "treatment outcome", to identify all relevant published literature. In addition, a thorough reference review of identified articles was conducted to ensure that all relevant articles were included.

\section{Study selection}

Articles identified from the search were imported into the Zotero reference manager with duplicates subsequently removed. The remaining articles were screened against the inclusion and exclusion criteria by a single reviewer (HK) by reviewing title, abstract, and the full-text articles subsequentially.

\section{Data collection, extraction, and data items}

Data extraction was conducted by one reviewer (HK). Generic study data were extracted from all articles such as study type, follow-up period, abscess size, number of participants, and participant demographics. Outcome measures extracted to answer the research questions from identified articles included presenting symptoms, the diagnostic method utilized, pathogens identified, specific treatment modality undergone, recurrence rates, re-admission rates within 30 days, success rate of treatment, and any mentioned advantages and disadvantages of each drainage approach. Successful treatment criteria were defined as a clinical improvement in symptoms or a decrease of more than half of the estimated abscess volume on follow-up TRUS, which could be compared between studies. ${ }^{[8]}$ Patients with continuing clinical symptoms or any identified recurrence of an abscess on follow-up were defined as treatment failures. ${ }^{[8]}$

\section{Risk of bias assessment}

The risk of bias of each study was assessed using the NewcastleOttawa scale (NOS) for observational studies. The scale consists of eight questions assessing the risk of introducing bias during selection, comparison, and outcome measurement. Nine stars can be obtained, and results are categorized into high-risk of bias (1-3 stars), moderate risk of bias (4-6 stars), and low risk of bias (7-9 stars).$^{[9,10]}$

\section{Results}

\section{Study selection}

A total of 683 articles were identified through the literature search, with three articles identified via reference review. Duplicate removal and initial screening excluded 535 articles. Of the 33 full-text articles assessed for eligibility, a final twelve articles were included in the review (Figure 1). 


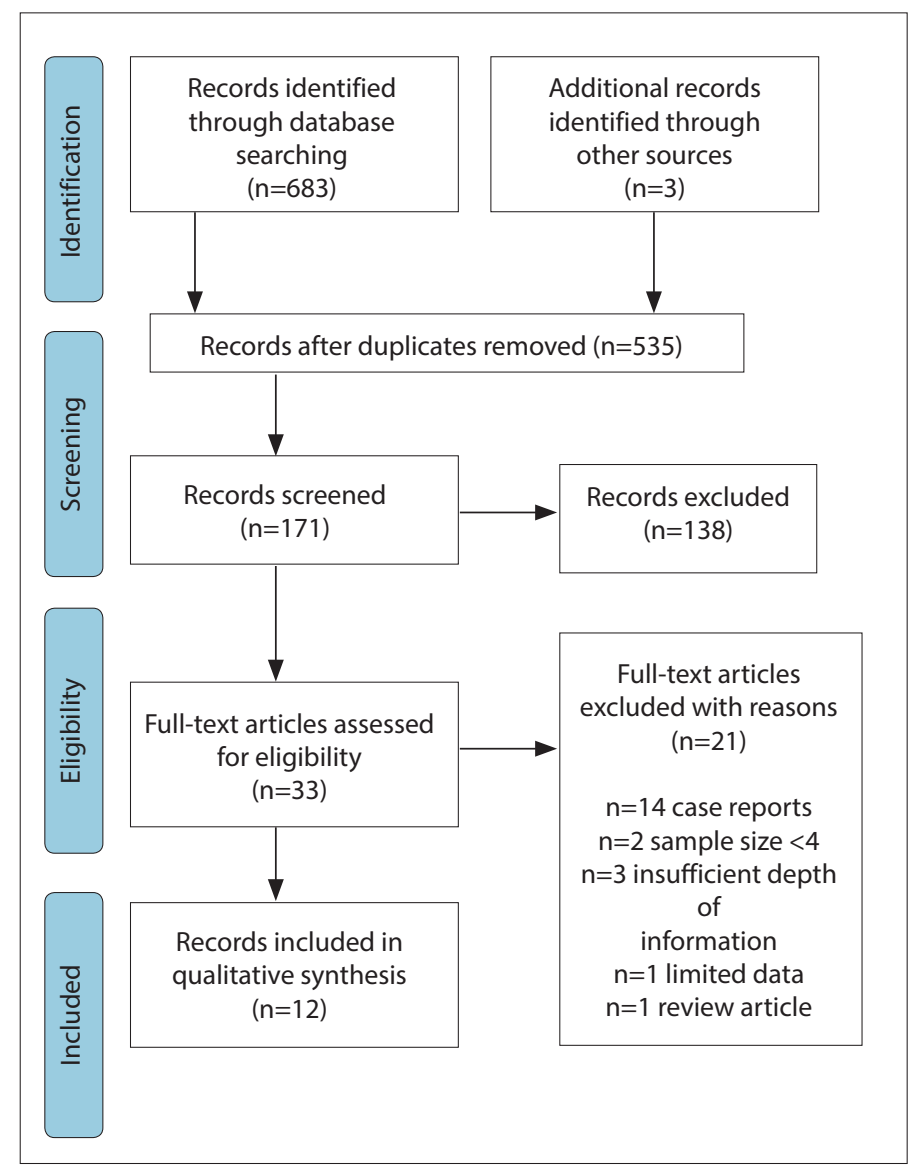

Figure 1. PRISMA diagram for study selection

\section{Study characteristics and result synthesis}

All included studies were observational, primarily retrospective cohort studies assessing demographic and clinical features of patients with PA, abscess size with an imaging modality, and management results. Results were divided into demographic and clinical features of disease at presentation, diagnostic modalities, management, and complications. Treatment options were classified through the approach utilized to reach the abscess; transperineal, transrectal, and transurethral. Across the twelve papers identified, a total of 210 male patients were present.

\section{Demographics and clinical presentation}

The mean age at diagnosis for patients was 58.8 years (range 35-72 years). A summary of the study characteristic of patients with abscesses within the identified articles is displayed in Table 1. A wide range of presenting features was seen (Figure 2) with the most common being lower urinary tract symptoms (LUTS) such as dysuria and frequency (67.1\% of patients). Fever was also commonly seen (61\%) along with acute urinary retention $(33.3 \%)$, perineal pain, or pain on defecation (16.6\%). Rarely, patients also presented with hematuria $(6.1 \%)$.

\section{Risk factors and co-morbidities}

Diabetes mellitus was the most common co-morbidity identified in abscess patients (50.9\% of cases). Other causes of immunosuppression including liver cirrhosis (1.4\%), renal failure $(0.95 \%)$, and two cases of HIV patients were seen presenting with tuberculous PAs. Finally, urinary tract outlet obstruction was present in $(5.7 \%)$. There were no co-morbid factors in $40.4 \%$ of the patients.

\section{Microbiology}

Various bacterial and fungal organisms were isolated in urinary and/or pus cultures (Figure 3), with Escherichia coli being the most prevalent pathogen in 101 cases (48\%). Other organisms reported included Klebsiella pneumoniae in 23 cases (11\%), Pseudomonas aeruginosa in 11 cases (5\%), Candida albicans in six cases (3\%), with the remaining 47 cases $(22.3 \%)$ demonstrating mixed bacteria. A culture was not undertaken in 22 patients $(10 \%)$.

\section{Diagnostic modalities}

Unexpectedly, transrectal ultrasonography (TRUS) was the most commonly used imaging tool identified for diagnosing PAs, with its use in 190 cases (90.5\%). The exact imaging strategy used across the studies was as follows: TRUS with CT or MRI scan was utilized in $99(47.1 \%)$ and five cases (2.4\%) respectively, only TRUS in 66 cases $(31.4 \%)$, only CT scan in 20 cases $(9.5 \%)$, abdominal ultrasound in 17 cases $(8.1 \%)$, and MRI alone in three cases $(1.5 \%)$.

\section{Management}

In total 210 patients underwent varying management modalities for a PA across the studies (Figure 4). PA characteristics varied among papers and patients undergoing different treatment options. The overall average abscess size across the papers was $3.88 \mathrm{~cm}(2.0-6.0 \mathrm{~cm})$, of which multifocal abscesses were seen in 55 cases $(26.2 \%)$ and five papers. ${ }^{[11-15]}$ The overall average hospital stay was 17.5 days (6-39 days). The interventions and outcomes of all studies identified have been summarized in Table 2 .

\section{Antibiotic treatment}

Most of the patients within the identified studies were administered antibiotics intravenously as their initial treatment modality. Almost all patients were started with a combination of ciprofloxacin with or without the addition of metronidazole. Interestingly, PAs were treated with conservative antibiotic treatment alone in $38(18.1 \%)$ patients, in six of the identified papers. This was often seen in patients where the abscess cavity was less than $1 \mathrm{~cm}$ in diameter, whereby a prolonged course of antibiotics was administered for one month. ${ }^{[4,8,11,15-17]}$ 


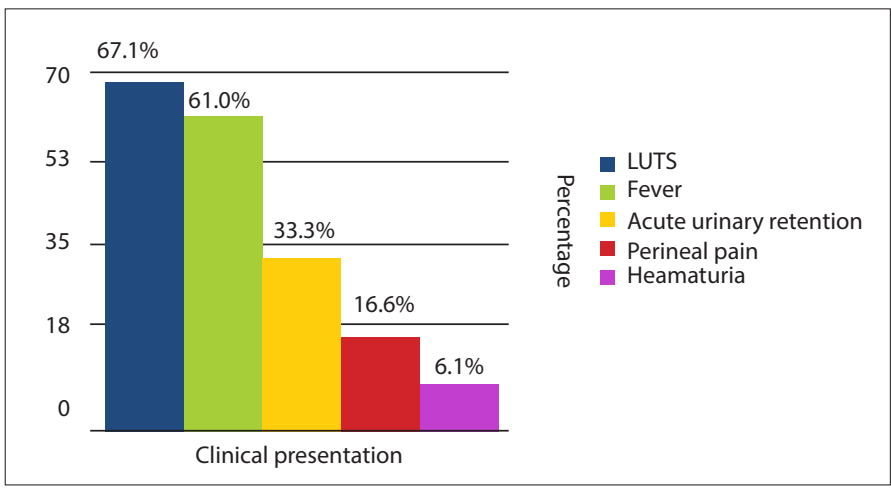

Figure 2. Symptoms in patients presenting with prostate abscess

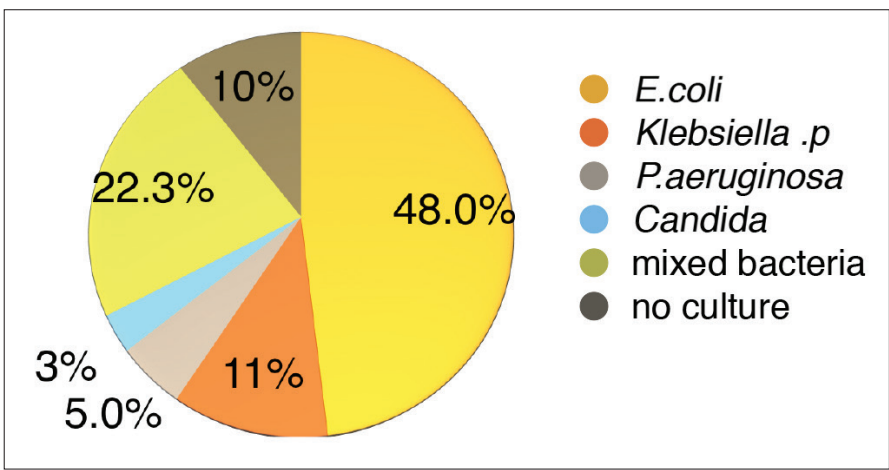

Figure 3. Most common organisms cultured in urine and/or pus culture in prostate abscess

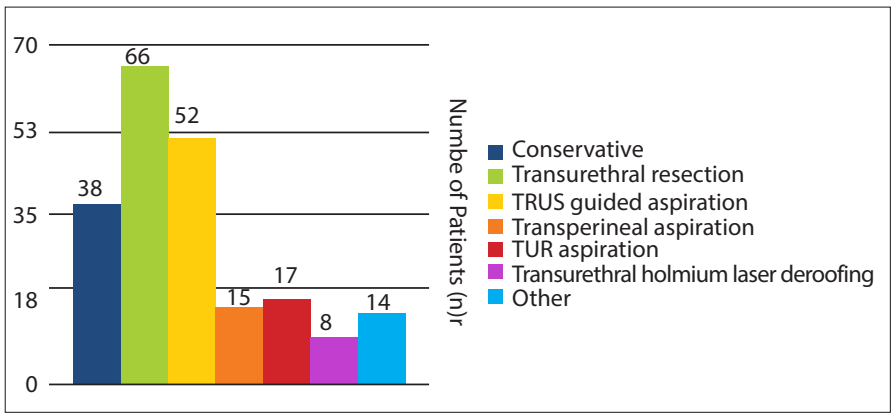

Figure 4. Comparison of patient numbers undergoing different treatment methods

The average hospital stay after conservative treatment was 19.08 (9-39 days) with two of the 38 patients (5.26\%) who underwent antibiotic treatment alone subsequently dying secondary to sepsis.

\section{Transperineal approach}

Transperineal aspiration was conducted in $15(7.1 \%)$ patients in five studies..$^{[12,16-19]}$ Of them, two (13.3\%) had a recurrence within one month, necessitating further transurethral deroofing for complete resolution of the abscess. Sonographically guided percutaneous transperineal aspiration did, however, have the lowest risk of complication compared to other surgical treatments. This was seen in a small case series of Barozzi et al. ${ }^{[16]}$ where all five cases showed rapid clinical improvement with a success rate of $100 \%$. Similarly, Tiwari et al..$^{[17]}$ also performed three out of their 19 cases through a transperineal approach with no recurrences.

\section{Transurethral approach}

Transurethral resection of the prostatic abscess (TURP) was the most common surgical approach used as seen in 73 (34.7\%) cases across ten papers..$^{[4,11,12,15,17-22]}$ This could be divided into those patients undergoing TURP as their first treatment procedure and those as their second treatment procedure once another had failed in 66 (31.4\%) and 7 (3.3\%) patients respectively. The average abscess size in those undergoing TURP treatment was $3.87 \mathrm{~cm}(3.0-4.0 \mathrm{~cm}) .^{[4,11,12,15,18-20]}$ Unexpectedly, the average hospital stay after TURP was 10.22 (6-15) days. In the largest study using TURP, Jang et al ${ }^{[4]}$ compared treatment modalities and their outcomes for PAs in 52 patients. It was found that patients treated with TURP had significantly shorter hospital stays compared to those undergoing TRUS-guided aspirations (10.2 vs. 23.25 days). Additionally, in a study conducted by El-Shazly et al. ${ }^{[21]}$, it was demonstrated that transurethral drainage achieved the highest success rates (100\%) without any major complications when compared to the other two drainage methods. Additional surgical manipulations were unnecessary in most cases treated with transurethral drainage.

Another transurethral approach investigated was transurethral deroofing (TUD) of the prostate. In a case series conducted by Tiwari et al. ${ }^{[17]}, 16$ out of 19 patients were treated with transurethral incision with deroofing of the cavity when the abscess was greater than $1 \mathrm{~cm}$ in size. Additionally, of the remaining three who underwent transperineal aspiration, one subsequently had a recurrence within one month, thereby necessitating a TUD. The overall success rate of those undergoing TUD was found to be $95.8 \%$. The smaller study by Jacobsen and Kvist ${ }^{[12]}$ also performed TUD for four patients, which were successful in clearing the abscess in all of them. Lee et al. ${ }^{[14]}$ proposed a novel method for TUD utilizing a holmium laser. In their prospective case series of eight patients, all abscesses were cleared successfully without recurrence with a mean length of stay post-surgery of 11.6 days. This method was also reported to resolve the predisposing condition of the prostatic abscess, such as bladder outlet obstruction or prostatic calcification. However, transient stress urinary incontinence was observed in three patients as a disadvantage, who were then managed conservatively. ${ }^{[14]}$ Furthermore, in a younger population, transurethral drainage could result in retrograde ejaculation as seen in three patients out of the 17 in a study conducted by Bhagat et al. ${ }^{[18]}$ (Table 3 ). 
Table 1. Summary of the characteristics of patients diagnosed with prostatic abscess

\begin{tabular}{|c|c|c|c|c|c|c|c|c|}
\hline Ref/No & $\begin{array}{l}\text { Mean age } \\
\text { (years) }\end{array}$ & Presentation & Risk factors & Microbiology & Imaging & $\begin{array}{l}\text { Abscess size/ } \\
\text { form }\end{array}$ & $\begin{array}{l}\text { Antibiotic } \\
\text { use }\end{array}$ & $\begin{array}{l}\text { Treatment } \\
\text { outcome }\end{array}$ \\
\hline 12 & $\begin{array}{l}65 \\
(5 \text { cases })\end{array}$ & $\begin{array}{l}\text { - } 2 \text { urinary reten- } \\
\text { tion \& irritative } \\
\text { bladder symptoms } \\
\text { - } 1 \text { stranguria and } \\
\text { frequency } \\
\text { - irritative bladder } \\
\text { symptoms and } \\
\text { perineal pain } \\
\text { - } 1 \text { pain in the lum- } \\
\text { bar region radiating } \\
\text { to the scrotum and } \\
\text { had suffered from } \\
\text { anal pain during } \\
\text { defecation }\end{array}$ & $2 \mathrm{DM}$ & $\begin{array}{l}\text { - } 4 \text { cases } \\
\text { Escherichia coli. } \\
\text { - } 1 \text { case } \text { Klebsiella } \\
\text { pneumoniae. } \\
\text { Streptococci. } \\
\text { - } 1 \text { case } \\
\text { Staphylococcus }\end{array}$ & TRUS & 2 multifocal & $\begin{array}{l}\text { - } 1 \text { case sulfa- } \\
\text { methoxazole } \\
\text { - remaining } \\
\text { intravenous } \\
\text { antibiotics. }\end{array}$ & $\begin{array}{l}2 \text { cases transureth- } \\
\text { ral resection, } \\
1 \text { case transrectal } \\
\text { incision. } \\
1 \text { case transperine- } \\
\text { al puncture, was } \\
\text { first performed, } \\
\text { but a transurethral } \\
\text { resection was } \\
\text { done later. } \\
1 \text { case transureth- } \\
\text { ral incision and } \\
\text { later a resection. }\end{array}$ \\
\hline 7 & $\begin{array}{l}59 \pm 11 \\
(13 \text { cases })\end{array}$ & $\begin{array}{l}\text { Urinary } \\
\text { frequency }(77 \%) \\
\text { Dysuria }(62 \%) \\
\text { Fever }(62 \%)\end{array}$ & $\begin{array}{l}\mathrm{DM}(38 \%), 1 \\
\text { urinary outlet } \\
\text { obstruction, } \\
\text { dialysis } \\
(15 \%)\end{array}$ & $\begin{array}{l}\text { Escherichia coli } \\
\text { ( } 2 \text { cases), Klebsi- } \\
\text { ella pneumoniae } \\
\text { (1 case), } \\
\text { Staphylococcus } \\
\text { (1 case) and } \\
\text { Enterococcus } \\
\text { faecalis (1 case). } \\
\text { - [positive } 62 \% \text { ] }\end{array}$ & $\begin{array}{l}\text { - all TRUS - } 4 \\
\text { patient s CT }\end{array}$ & $\begin{array}{l}\text { - smaller than } 1 \\
\text { cm (1 case) } \\
\text { - large abscesses } \\
>1 \mathrm{~cm}<3 \mathrm{~cm}(12 \\
\text { cases) } \\
\text { - }>3 \mathrm{~cm} \text { ( } 3 \text { cases) } \\
\text { - well-defined in } \\
8 \text { patients }(62 \%) \\
\text { and poorly defi- } \\
\text { ned in } 5(38 \%\end{array}$ & $\begin{array}{l}\text { IV } \\
\text { ciprofloxacin }\end{array}$ & \\
\hline 20 & $\begin{array}{l}55.6 \\
\text { (6 cases) }\end{array}$ & $\begin{array}{l}\text { dysuria }(83.3 \%) \\
\text { fever, } 1 \text { perineal } \\
\text { pain, acute urinary } \\
\text { retention }\end{array}$ & $\begin{array}{l}\text { DM }(33.3 \%) \text {, } \\
\text { UTI }(33.3 \%) \text {, } \\
\text { bladder } \\
\text { outflow } \\
\text { obstruction } \\
(16.6 \%)\end{array}$ & $\begin{array}{l}\text { Escherichia coli } \\
\text { Only in } 1 \text { patient }\end{array}$ & $\begin{array}{l}\text { all TRUS and } \\
1 \mathrm{CT}\end{array}$ & $\begin{array}{l}\text { Well-defined } \\
\text { Thick wall (66.6) } \\
\text { Irregular contour } \\
\text { (33.3) }\end{array}$ & $\begin{array}{l}\text { Antibiotic } \\
\text { prophylaxis } \\
\text { with oral } \\
\text { quinolone and } \\
\text { IM metroni- } \\
\text { dazole was } \\
\text { started the } \\
\text { day before } \\
\text { the aspiration } \\
\text { and continued } \\
\text { with par- } \\
\text { enteral anti- } \\
\text { biotic therapy } \\
\text { according to } \\
\text { the culture } \\
\text { results. }\end{array}$ & $\begin{array}{l}\text { TRUS-guided } \\
\text { needle aspiration. } \\
\text { - Only } 1 \text { patient } \\
\text { with bladder } \\
\text { outflow obstructi- } \\
\text { on, had recurrence } \\
\text { within } 3 \text { weeks. } \\
\text { - He underwent } \\
\text { transurethral } \\
\text { resection of the } \\
\text { prostate } \\
\text { (TUR-P). }\end{array}$ \\
\hline
\end{tabular}


Table 1. Summary of the characteristics of patients diagnosed with prostatic abscess (Continue)

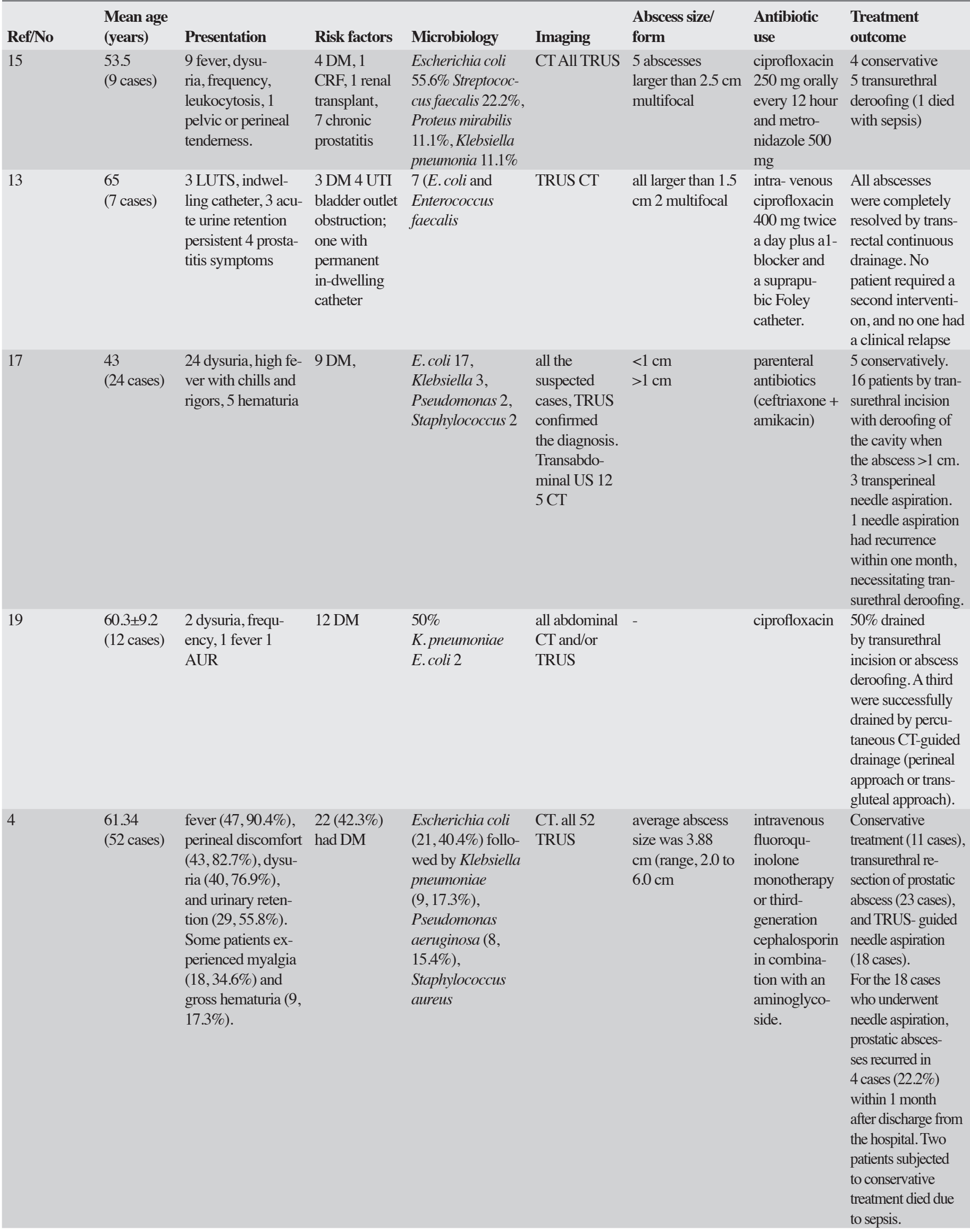




\section{Table 1. Summary of the characteristics of patients diagnosed with prostatic abscess (Continue)}

\begin{tabular}{|c|c|c|c|c|c|c|c|c|}
\hline Ref/No & $\begin{array}{l}\text { Mean age } \\
\text { (years) }\end{array}$ & Presentation & Risk factors & Microbiology & Imaging & $\begin{array}{l}\text { Abscess size/ } \\
\text { form }\end{array}$ & $\begin{array}{l}\text { Antibiotic } \\
\text { use }\end{array}$ & $\begin{array}{l}\text { Treatment } \\
\text { outcome }\end{array}$ \\
\hline 14 & $\begin{array}{l}66 \\
\text { ( } 8 \text { cases })\end{array}$ & $\begin{array}{l}\text { Dysuria }(100 \%) \text {. } \\
\text { Four patients } \\
(66.6 \%) \text { had } \\
\text { Perineal pain. } \\
\text { Three Patients } \\
(37.5 \%) \text { presented } \\
\text { with acute urinary } \\
\text { retention }\end{array}$ & $\begin{array}{l}3(37.5 \%) \\
\text { had DM, } \\
3(37.5 \%) \\
\text { indwelling } \\
\text { urethral } \\
\text { catheter, } 2 \\
(25 \%) \text { history } \\
\text { of urethral } \\
\text { injury. }\end{array}$ & $\begin{array}{l}\text { Staphylococcus } \\
\text { aureus Klebsiella } \\
\text { Enterococcus } \\
\text { faecalis } \\
\text { Pseudomonas } \\
\text { aeruginosa E. } \\
\text { coli } 1\end{array}$ & $\begin{array}{l}\text { All } 8 \text { CT } \\
\text { TRUS }\end{array}$ & $\begin{array}{l}\text { All multiloculated } \\
\text { or multifocal } \\
\text { abscess }\end{array}$ & $\begin{array}{l}\text { intravenous } \\
\text { third- } \\
\text { generation } \\
\text { cephalosporin } \\
\text { in combinati- } \\
\text { on with met- } \\
\text { ronidazole. }\end{array}$ & $\begin{array}{l}\text { transurethral } \\
\text { holmium laser } \\
\text { deroofing all suc- } \\
\text { cess. Transient } \\
\text { stress incontinence } \\
\text { was observed in } \\
\text { three patients. It } \\
\text { subsided within } \\
\text { three weeks in } \\
2 \text { patients and } \\
\text { improved with } \\
\text { conservative ma- } \\
\text { nagement within } \\
\text { two months in the } \\
\text { remaining patient. }\end{array}$ \\
\hline 18 & $\begin{array}{l}59.22 \pm \\
11.02 \\
\text { and } \\
49.14 \pm \\
15.67 \\
\text { (48 cases) }\end{array}$ & $\begin{array}{l}33 \text { pyrexia } 33 \text { AUR } \\
\text { 39LUTS }\end{array}$ & $\begin{array}{l}30 \text { DM } 2 \text { pati- } \\
\text { ents with HIV } \\
\text { had Tuber- } \\
\text { culous PA, } 1 \\
\text { CRF, } 1 \text { Liver } \\
\text { cirrhosis }\end{array}$ & $\begin{array}{l}20 \text { Escherichia } \\
\text { coli } 4 \text { Staphylo- } \\
\text { coccus aureus } \\
1 \text { Pseudomonas } \\
\text { aeruginosa }\end{array}$ & $\begin{array}{l}\text { abdominal } \\
\text { us } 15 \text { cases } \\
\text { TRUS } 20 \\
\text { CT } 3\end{array}$ & & $\begin{array}{l}\text { ampicillin, } \\
\text { ciprofloxacin, } \\
\text { co- trimo- } \\
\text { xazole and } \\
\text { gentamicin }\end{array}$ & $\begin{array}{l}14 \text { TURP, } 17 \\
\text { TUR drainage, } 4 \\
\text { aspiration } 3 \text { had } \\
\text { retrograde ejacu- } \\
\text { lation following } \\
\text { TUR drainage }\end{array}$ \\
\hline
\end{tabular}

E. coli: Escherichia coli; PA: prostate abscess; LUTS: lower urinary tract symptoms; AUR: acute urinary retention; CRF: chronic renal failure; US: ultrasound; CDU: color Doppler ultrasound; TRUS: transrectal ultrasound scan; CT: computed tomography; MRI: magnetic resonance imaging; TURP: transurethral resection of prostate

\section{Transrectal approach}

TRUS-guided needle aspiration was conducted in 52 (24.8\%) patients across seven studies. ${ }^{[4,7,11,15,17-20]}$ Of these, the abscess recurred in eleven cases $(21.2 \%)$. In three cases, the abscess was over $3 \mathrm{~cm}$ and required re-aspiration twice due to recurrence within three days. In five cases, recurrence occurred within one month after discharge with the remaining three transrectal aspirations failing initially and therefore requiring transurethral resection. The average abscess size in those undergoing TRUS-guided needle aspiration treatment was quite large at $4.04 \mathrm{~cm}(2.0-5.0$ $\mathrm{cm})$. Additionally, the average hospital stay was seen to be long after TRUS-guided needle aspiration at 23.25 (18-34) days.

The study by Oshinomi et al. ${ }^{[11]}$ demonstrates the importance of assessing the size and shape of the abscess for guiding management. In their study, all cases consisted of multiple abscesses with a long axis exceeding $3 \mathrm{~cm}$. However, in those undergoing TRUS-guided aspiration, three failed subsequently requiring TURP for complete resolution meaning a success rate of $83.3 \%$ was achieved. Similar success rates were achieved by Göğüş et al. ${ }^{[20]}$, where six patients underwent TRUS-guided needle aspiration as their treatment of PA, being successful in five of them $(83.3 \%)$.

A single study conducted by Chou et al.$^{[8]}$ assessed the addition of color Doppler ultrasonography (CDU) to help guide the TRUS aspiration in 13 patients. It was found that abscesses with poorly defined boundaries had more prominent surrounding color-flow signals and with CDU guidance achieved, with relative difficulty, a satisfactory aspiration procedure in all patients. As a result, no surgical drainage was needed in any patients with follow-up transrectal CDU, demonstrating a good response to the treatment and complete resolution of the abscess cavity in all cases.

Lastly, a single study was found which advocated leaving an indwelling catheter in the abscess following drainage to allow complete evacuation. Aravantinos et al. ${ }^{[13]}$ reported a $100 \%$ success rate following TRUS-guided aspiration with subsequent 
Table 2. Comparison of surgical interventions and outcomes for the management of prostatic abscesses

No. Study

$1 \quad$ Jacobsen and

Kvist $^{[12]} 1993$
Pt.N. Abscess size/form

$5 \quad 2$ multifocal
Treatment outcome

2 cases transurethral resection,

1 case transrectal incision. 1 case transperineal puncture was first performed, but a transurethral resection was done later.

1 case transurethral incision and later a resection.
2 Barozzi et al. ${ }^{[16]} \quad 8 \quad 4$ peripheral 4 central size range 1998 $(1.5$ and $4.0 \mathrm{~cm})$

3

Chou et al.$^{[8]} 2004 \quad 13$

4 Göğüş et al. ${ }^{[20]} \quad 6$ 2004

$6 \quad$ Well-defined, thick wall (66.6) Irregular contour (33.3)

abscesses $>1 \mathrm{~cm}<3 \mathrm{~cm}(12$ cases) $>3 \mathrm{~cm}$ ( 3 cases) welldefined in 8 patients $(62 \%)$ and poorly defined in $5(38 \%)$

2004

\begin{tabular}{|c|c|c|c|}
\hline 5 & $\begin{array}{l}\text { Al-Meshaan et } \\
\text { al. }{ }^{[15]} 2008\end{array}$ & 9 & $\begin{array}{l}5 \text { abscesses larger than } 2.5 \mathrm{~cm} \\
\text { multifocal }\end{array}$ \\
\hline 6 & $\begin{array}{l}\text { Aravantinos et } \\
\text { al. }{ }^{[13]} 2008\end{array}$ & 7 & $\begin{array}{l}\text { all larger than } 1.5 \mathrm{~cm} 2 \text { multi- } \\
\text { focal }\end{array}$ \\
\hline
\end{tabular}

Tiwari et al. ${ }^{[17]} \quad 24<1 \mathrm{~cm}>1 \mathrm{~cm}$
2011

$8 \quad$ Wen et al. ${ }^{[19]} 2012 \quad 12$

$9 \quad$ Jang et al. ${ }^{[4]} 2012 \quad 52$

average abscess size was 3.88 $\mathrm{cm}$ (range, 2.0 to $6.0 \mathrm{~cm}$

(n)

$3 / 8$ refused surgical or sonographically guided drainage. All 5 cases percutaneous transperineal sonographically guided aspiration produced rapid clinical improvement and resolved the pain and fever.

Aspiration. No surgical drainage was needed in these 13 patients. Follow-up TRUS CDU showed good response to the treatment with complete resolution of the abscess cavity in all cases

TRUS-guided needle aspiration. Only 1 patient with $83.3 \%$ bladder outflow obstruction, had recurrence within 3 weeks. He underwent transurethral resection of the prostate (TURP).

4 Conservative transurethral deroofing (1 died with sepsis)

All abscesses were completely resolved by transrectal continuous drainage. No patient required a second intervention, and no one had a clinical relapse

5 conservatively. 16 patients by transurethral incision with deroofing of the cavity when the abscess $>1 \mathrm{~cm} .3$ transperineal needle aspiration. 1 needle aspiration had recurrence within one month, necessitating transurethral deroofing.

$50 \%$ drained by transurethral incision or abscess $75 \%$ unroofing. A third 4 cases were successfully drained by percutaneous CT-guided drainage (perineal approach or transgluteal approach). 3 died after TUR, transperineal aspiration

Conservative treatment (11 cases), transurethral resection of prostatic abscess (23 cases), and TRUS-guided needle aspiration (18 cases). In 18 cases who underwent needle aspiration, prostatic abscesses recurred in 4 cases (22.2\%) within 1 month after discharge from the hospital. Two patients subjected to conservative treatment died due to sepsis.

$10 \quad$ Lee et al. ${ }^{[14]} 2015 \quad 8$

All multiloculated or multifocal abscess

Transurethral holmium laser deroofing all successful. Transient stress urinary incontinence was observed in three patients. It subsided within three weeks in two patients and improved with conservative management within two months in the remaining patient.

All conservative. 5 drainage was transrectal or transurethral. There were no cases of transperineal drainage. 3 transrectal failed needed 3 TURP

14 TURP, 17 TUR drainage, 4 aspiration 3 had retrogra- $\quad 93.75 \%$ de ejaculation following TUR drainage

Success rate

$60 \%$

$100 \%$

$100 \%$

$83.3 \%$

$100 \%$

$95.8 \%$

$88.4 \%$

$62.5 \%$

$83.3 \%$ 2018

12 Bhagat et al. ${ }^{[18]} \quad 48 \quad$ Multifocal $60 \%$ abscess $>3 \mathrm{~cm}$ 2008

PA: prostate abscess; US: ultrasound; CDU: color Doppler ultrasound; TRUS: transrectal ultrasound scan; CT: computed tomography; TURP: transurethral resection of prostate 


\section{Table 3. Pros \& cons of drainage approaches}

\begin{tabular}{|c|c|c|}
\hline $\begin{array}{l}\text { Drainage } \\
\text { approach }\end{array}$ & Advantage & Disadvantage \\
\hline Transrectal & $\begin{array}{l}\text { Simple procedure, } \\
\text { less pain }\end{array}$ & $\begin{array}{l}\text { Recurrence } \\
\mathrm{P} / \mathrm{R} \text { bleeding } \\
\text { Exacerbation of infection }\end{array}$ \\
\hline Transperineal & Thick needle & $\begin{array}{l}\text { Painful } \\
\text { Sexual dysfunction } \\
\text { Nerve damage }\end{array}$ \\
\hline Transurethral & Adequate drainage & $\begin{array}{l}\text { Invasive procedure } \\
\text { Sexual dysfunction } \\
\text { Incontinence } \\
\text { Exacerbation of infection }\end{array}$ \\
\hline
\end{tabular}

continuous drainage, of which $29 \%$ of patients initially had multifocal PAs.

\section{Quality assessment of articles}

All included studies were observational, primarily retrospective cohort investigations. Risk of bias assessment for individual studies measured by the NOS ranged between five and nine with a median value of eight. Most of the studies assessed were found to contain a low risk of bias (Appendix 1).

\section{Discussion}

This systematic review provides an overview of the common demographics, presentations, diagnostic tools available, and management options for PAs. PAs remains an infrequent clinical occurrence, accounting for only $0.5 \%$ of all prostatic diseases. [23] This is largely attributed to the widespread use of broadspectrum antibiotics. However, it remains a difficult diagnosis to make as the clinical presentation often mimics that of several other diseases of the lower urinary tract. ${ }^{[11,18]}$ However, PAs are an important diagnosis to consider as when it is not adequately treated or when there is a delay in treatment, there is a frequent progression to sepsis and death. ${ }^{[23,24]}$

A PA can occur in patients of any age but is mainly found in men in their $5^{\text {th }}$ and $6^{\text {th }}$ decade of life ${ }^{[25]}$ While in the pre-antibiotic era, Neisseria gonorrhoeae was the primary organism, at present gram- negative bacilli (mostly E. coli) have been estimated to cause about $60-80 \%$ of cases. ${ }^{[17]}$ This is consistent with the findings within our review where $E$. coli was responsible for $48 \%$ of cases. However, as identified within the literature, it is also important to consider other significant pathogens including Pseudomonas species, Staphylococcus species, and occasionally anaerobic bacteria to ensure that an appropriate antimicrobial cover is initially given before culture results.
Symptoms and clinical findings of PAs were seen to be extremely variable in the literature, which can make the diagnosis difficult. LUTS, perineal pain, and fever are commonly seen, but unfortunately, these symptoms overlap with those of acute prostatitis. It is, therefore, important to have a low threshold for suspecting an abscess and investigate with appropriate diagnostic imaging, especially if symptoms do not improve after 48 hours of intravenous antibiotic therapy ${ }^{[5]}$ Increasingly, the evidence points to the emergence of TRUS as the first-line diagnostic modality for PAs as seen by the high utilization within the identified studies $(90.5 \%$ of cases). However, CT and MRI offer important additional modalities to consider but should ideally be reserved for those in whom TRUS is not tolerated or contraindicated and when dealing with abscesses that have extended beyond the prostate. ${ }^{[16,20]}$

It is important to consider predisposing factors. The common co-morbidities in our review included diabetes mellitus, bladder outlet obstruction, an indwelling catheter, chronic renal failure, hemodialysis, chronic liver disease, and HIV infection. ${ }^{[18]}$ Of these, by far the most common associating disease in our review was diabetes because a neurogenic bladder may coexist. ${ }^{[26]}$ An additional important consideration in diabetic patients is that because the state of urination before the onset of the abscess is often unknown, it may be difficult for the treatment policy to rely on the volume of the prostate. ${ }^{[11]}$ This highlights the importance of assessing the volume of the prostate and evaluating the size and shape of the abscess using TRUS, CT, or magnetic resonance imaging ${ }^{[4]}$ Finally, the identification of these co-morbidities is important to achieve optimum treatment. It is important to correct abnormalities such as ensuring good glycemic control in diabetes, renal replacement in chronic renal failure, or management of uremia in liver failure to ensure the best outcomes can be achieved subsequentially. ${ }^{[27]}$

Several approaches for the drainage of PAs have been proposed in the literature as identified in this review. It is, however, important to interpret this with caution as studies and patients remain very heterogeneous. The treatment of PAs is at present complicated by a lack of high-quality evidence on which to base clinical decisions. Case reports and expert opinion reviews account for a large majority of published data regarding PAs with only a few case series reported as seen in this review. The lack of robust prospective treatment and epidemiological data has prevented the development of diagnostic and treatment guidelines and has limited our understanding of the true incidence of PAs and the associated microbial and host risk factors.

Despite the lack of high-quality evidence, we have proposed an algorithm to manage PAs patients based on the current best evidence and our experience (Figure 5). Those with small abscesses $(<2 \mathrm{~cm})$ were seen to potentially respond well to antibiotics alone. ${ }^{[28]}$ However, their progress requires careful monitoring clinically 


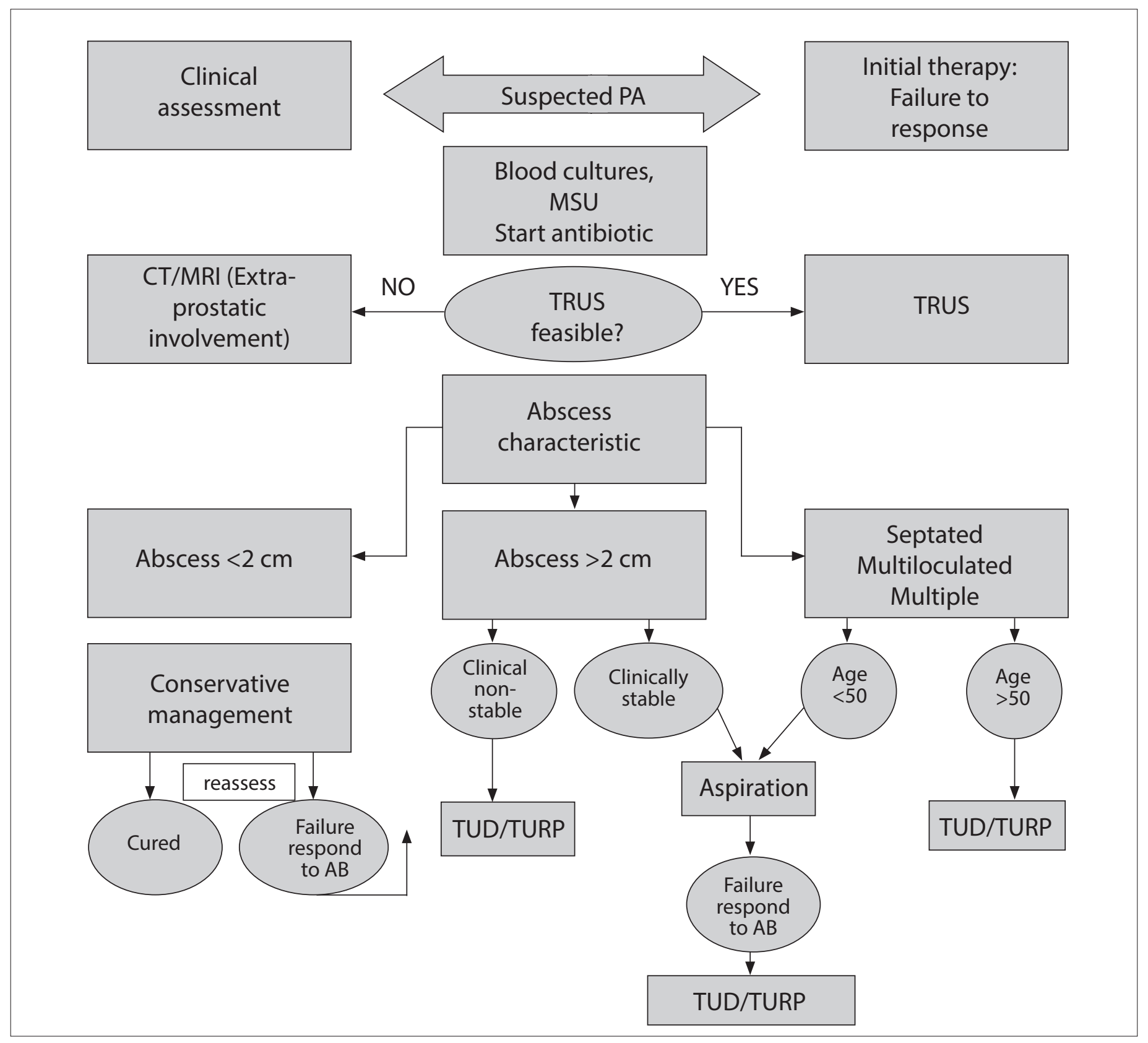

Figure 5. Suggested treatment algorithm for patients presenting with prostate abscess

DRE: digital rectal exam; PA: prostate abscess; MSU: mid-stream urine; TRUS: transrectal ultrasound scan; CT: computed tomography; MRI: magnetic resonance imaging; TURP: transurethral resection of prostate.

or thorough serial imaging. Transrectal drainage may act as the next step up from this, but should largely be reserved for patients presenting with a simple abscess in a clinically stable condition. TRUS-guided aspiration offers a modality that can be used effectively to diagnose, treat, and follow the clinical progression. TRUS-guided drainage should precede any transurethral drainage in these patients due to the potential risk of sexual dysfunction or severe complications arising from transurethral procedures, particularly in young men who wish to preserve continence and fertility. ${ }^{[5]}$ The current evidence supports the use of TRUS-guided needle aspiration as a feasible alternative to transurethral drainage with success rates. ${ }^{[6]}$ However, close monitoring following aspiration remains important, particularly in large PAs due to the possibility of failure or recurrence.

Utilizing a transperineal approach for drainage was identified as allowing for rapid assessment and drainage of the abscess without the need for general anesthetic. However, the perineal 
incision may be more painful for the patient with the potential to lead to impotence due to nerve damage..$^{[1]}$ While in our review, overall low complication rates were seen, this was the least utilized modality, and hence was the least evidence-based method identified. There was additional evidence of some recurrences within the literature. ${ }^{[29,30]}$ As such we have recommended the TRUS-guided approach within our algorithm at present. However, with the growing utilization of the transperineal approach in prostatic biopsies, the evidence for its use in PAs may increase in the future.

Due to the need for more definitive drainage in clinically unwell patients, we would recommend transurethral approaches either via resection or deroofing of the abscess. Similarly, in those with more complex or multiloculated PA, those who are older and hence may have less need for fertility-preserving treatment, or those in whom an element of bladder outlet obstruction is present, a transurethral approach is recommended due to the risk of recurrence. ${ }^{[18,31]}$ Finally, those who have failed TRUSguided aspiration will similarly benefit from more definitive re-drainage through transurethral surgical management. Several transurethral approaches have been described at present, including TURP, TUD, and holmium laser enucleation. All have demonstrated great success rates within the identified literature at present; however, with minimal comparative data available, it is difficult to provide any recommendation for one approach over another at present.

It is important to consider the complications observed post procedures. As expected, the transurethral approach demonstrated higher rates of complication compared to aspiration alone. These included septic shock, epididymo-orchitis, urethral diverticulum, and urethral strictures. ${ }^{[26]}$ Other known complications of the transurethral approach were seen in five out of twelve papers including retrograde ejaculation, urinary incontinence, and the systemic spread of organisms via communicating venous drainage. These are important to consider when planning which approach to undertake for the resolution of the abscess.

It is clear from this review that further investigation is required within the area of PAs to allow the formulation of evidencebased guidelines. There is a need for larger, ideally randomized studies to investigate current management options including the efficacy of antibiotic treatment in smaller PAs as compared to aspiration. Furthermore, as the transperineal route becomes increasingly used within urology, the best approach of aspiration requires further research to compare it to the transrectal method directly in terms of success rates and complications. Finally, comparative studies comparing different transurethral treatment options are needed to identify both the best approach and patient subgroups who would benefit from different approaches.
As with any study, this review does have its limitations, of which, the most important was the quality of the included studies. This review was based on observational non-randomized studies, thereby introducing the risk for confounding factors to affect the results. Furthermore, despite a comprehensive and broad search strategy, relevant pertinent articles could still have been missed. Finally, this review was not registered prospectively through a database such as PROSPERO due to having completed data extraction at the time of registration.

In conclusion, the diagnosis and treatment practices of PAs are, at present, widely varied and depend on patient and surgeon preference due to the lack of clear guidelines. However, while deciding on the best approach for drainage, it is important to assess the size and shape of the abscess using transrectal ultrasonography (TRUS) or with additional adjunctive imaging such as CT or MRI. Small abscesses $(<2 \mathrm{~cm})$ may be initially treated with a trial of prolonged antibiotic administration. However, transrectal drainage may be required in cases of failed antibiotic treatment and larger abscesses. In those with failed TRUS-guided drainage, transurethral drainage should be considered. Transurethral drainage should also be considered in cases of complex or multiple abscesses in the elderly due to frequent co-existence of bladder outlet obstruction and less need for fertility-sparing treatments. While transurethral drainage offered shorter hospital stays and more definitive abscess clearance, postoperative complications were frequent. However, at present, the evidence base surrounding the diagnosis and management of PAs remains poor, and further research is certainly needed to determine the best treatment modalities for different sizes and types of prostatic abscesses. Nevertheless, the findings in this review can be used to guide the physician in deciding on the approach for drainage with early diagnosis and treatment.

Peer-review: Externally peer-reviewed.

Author Contributions: Concept - H.K., K.A.; Design - H.K., O.B., K.A.; Supervision - G.M., R.J., A.K., K.A.; Resources - H.K., K.A.; Materials - H.K.; Data Collection and/or Processing - H.K.; Analysis and/or Interpretation - H.K., O.B., G.M., K.A.; Literature Search H.K.; Writing Manuscript - H.K., O.B.; Critical Review - G.M., R.J., A.K., K.A.

Acknowledgements: OB acknowledges research support from the National Institute for Health Research and the MRC Centre for Transplantation at King's College London. KA acknowledges research support from the Pelicans Group, MRC Centre for Transplantation at Kings College London and NIHR. KA acknowledges funding from the Royal College of Surgeons of England, The Urology Foundation, Coptcoat Charity, and Medtronics (educational consultant for Einstein Project). 
Conflict of Interest: The authors have no conflicts of interest to declare.

Financial Disclosure: The authors declared that this study has received no financial support.

\section{References}

1. Faris G, Metz Y, Friedman B, Appel B, Stein A. [Prostatic abscess-diagnosis and treatment]. Harefuah 2008;147:594-6.

2. Brawer MK, Stamey TA. Prostatic abscess owing to anaerobic bacteria. J Urol 1987;138:1254-5. [Crossref]

3. Cytron S, Weinberger M, Pitlik SD, Servadio C. Value of transrectal ultrasonography for diagnosis and treatment of prostatic abscess. Urology 1988;32:454-8. [Crossref]

4. Jang K, Lee DH, Lee SH, Chung BH. Treatment of Prostatic Abscess: Case Collection and Comparison of Treatment Methods. Korean J Urol 2012;53:860-4. [Crossref]

5. Collado A, Palou J, García-Penit J, Salvador J, de la Torre P, Vicente J. Ultrasound- guided needle aspiration in prostatic abscess. Urology 1999;53:548-52. [Crossref]

6. Gan E. Transrectal ultrasound-guided needle aspiration for prostatic abscesses: an alternative to transurethral drainage? Tech Urol 2000;6:178-84

7. Moher D, Liberati A, Tetzlaff J, Altman DG. Preferred Reporting Items for Systematic Reviews and Meta-Analyses: The PRISMA Statement. PLoS Med 2009; 6. Available from: https:// www.ncbi. nlm.nih.gov/pmc/articles/PMC2707599/ [Crossref]

8. Chou YH, Tiu CM, Liu JY, Chen JD, Chiou HJ, Chiou SY, et al. Prostatic abscess: transrectal color Doppler ultrasonic diagnosis and minimally invasive therapeutic management. Ultrasound Med Biol 2004;30:719-24. [Crossref]

9. Reeves BC, Deeks JJ, Higgins JP, Wells GA. Including Non-Randomized Studies. In: Cochrane Handbook for Systematic Reviews of Interventions [Internet]. John Wiley \& Sons, Ltd; 2008 [cited 2019 Dec 10]. p. 389-432. Available from: https:// onlinelibrary. wiley.com/doi/abs/10.1002/9780470712184.ch13 [Crossref]

10. Wells GA, Tugwell P, O’Connell D, Welch V, Peterson J, Shea B, et al. The Newcastle-Ottawa Scale (NOS) for assessing the quality of nonrandomized studies in meta-analyses. 2015 Jan 1 [cited 2019 Dec 10]; Available from: https:// www.scienceopen.com/ document?vid=54b48470-4655-4081-b5d4-e8ebe8d1792e

11. Oshinomi K, Matsui Y, Unoki T, Shimoyama H, Nakasato T, Morita J, et al. Treatment strategy for prostatic abscess: Eighteen cases' report and review of literature. Urological Sci 2018;29:206. [Crossref]

12. Jacobsen JD, Kvist E. Prostatic abscess. A review of literature and a presentation of 5 cases. J Urol 1993;27:281-4. [Crossref]

13. Aravantinos E, Kalogeras N, Zygoulakis N, Kakkas G, Anagnostou T, Melekos M. Ultrasound-guided transrectal placement of a drainage tube as therapeutic management of patients with prostatic abscess. J Endourol 2008;22:1751-4. [Crossref]
14. Lee CH, Ku JY, Park YJ, Lee JZ, Shin DG. Evaluation of holmium laser for transurethral deroofing of severe and multiloculated prostatic abscesses. Korean J Urol 2015;56:150-6. [Crossref]

15. Al-Meshaan M, Hameed MA, Al-Sairafy A, Kamber H. Our Experience in the Management of Prostatic Abscess. Kuwait Medical J 2008;40:281-4.

16. Barozzi L, Pavlica P, Menchi I, De Matteis M, Canepari M. Prostatic abscess: diagnosis and treatment. J Roentgenol 1998;170:7537. [Crossref]

17. Tiwari P, Pal DK, Tripathi A, Kumar S, Vijay M, Goel A, et al. Prostatic abscess: diagnosis and management in the modern antibiotic era. Saudi J Kidney Dis Transpl 2011;22:298-301.

18. Bhagat, Kekre NS, Gopalakrishnan G, Balaji V, Mathews MS. Changing profile of prostatic abscess. Int Braz J Urol 2008;34:16470. [Crossref]

19. Wen SC, Juan YS, Wang CJ, Chang K, Shih MCP, Shen JT, et al. Emphysematous prostatic abscess: case series study and review. Int J Infect Dis 2012;16:e344-9. [Crossref]

20. Göğüş C, Ozden E, Karaboğa R, Yağci C. The value of transrectal ultrasound guided needle aspiration in treatment of prostatic abscess. Eur J Radiol 2004;52:94-8. [Crossref]

21. El-Shazly M, El- Enzy N, El-Enzy K, Yordanov E, Hathout B, Allam A. Transurethral Drainage of Prostatic Abscess: Points of Technique. Nephrourol Mon 2012;4:458-61. [Crossref]

22. Trauzzi SJ, Kay CJ, Kaufman DG, Lowe FC. Management of prostatic abscess in patients with human immunodeficiency syndrome. Urology 1994;43:629-33. [Crossref]

23. Granados EA, Riley G, Salvador J, Vincente J. Prostatic abscess: diagnosis and treatment. J Urol 1992;148:80-2. [Crossref]

24. Ackerman AL, Parameshwar PS, Anger JT. Diagnosis and treatment of patients with prostatic abscess in the post-antibiotic era. Int J Urol 2018;25:103-10. [Crossref]

25. Pai MG, Bhat HS. Prostatic abscess. J Urol 1972;108:599-600. [Crossref]

26. Elshal AM, Abdelhalim A, Barakat TS, Shaaban AA, Nabeeh A, Ibrahiem EH. Prostatic abscess: Objective assessment of the treatment approach in the absence of guidelines. Arab J Urol 2014;12:262-8. [Crossref]

27. Lin YT, Wang FD, Wu PF, Fung CP. Klebsiella pneumoniae liver abscess in diabetic patients: association of glycemic control with the clinical characteristics. BMC Infect Dis 2013;13:56. [Crossref]

28. Ridgway AJ, Luk ACO, Pearce I. Prostate abscess: A comprehensive review of the literature. J Clin Urol 2019;2051415819850996.

29. Elwagdy S, Abdelkhalek M, El-Kheshen A, Aun AA, Mostafa A. Role of transrectal sectional sonography (TRSS) in management of prostatic abscesses. Urol Ann 2015;7:334-8. [Crossref]

30. Oliveira P, Andrade JA, Porto HC, Filho JEP, Vinhaes AFJ. Diagnosis and treatment of prostatic abscess. Int Braz J Urol 2003;29:304. [Crossref]

31. Vyas JB, Ganpule SA, Ganpule AP, Sabnis RB, Desai MR. Transrectal ultrasound- guided aspiration in the management of prostatic abscess: A single-center experience. Indian J Radiol Imaging 2013;23:253-7. [Crossref] 
Appendix 1. Presentation of 12 included studies

\begin{tabular}{|c|c|c|c|c|c|c|c|c|}
\hline \multicolumn{3}{|c|}{ Article information } & \multirow{2}{*}{$\frac{\text { Population }}{\text { Prostate Abscess }}$} & \multicolumn{4}{|c|}{ Intervention } & \multirow{2}{*}{$\frac{\text { Risk of bias }}{\text { NOS score }}$} \\
\hline Authur & Year & Study design & & AB & Transperineal & Transrectal & Transurethral & \\
\hline Jacobsen and Kvist ${ }^{[12]}$ & 1993 & case series & 5 & $\mathrm{X}$ & $\mathrm{X}$ & $\mathrm{X}$ & $\mathrm{X}$ & 7 \\
\hline Barozzi et al. ${ }^{[16]}$ & 1998 & Cohort & 8 & $X$ & $\mathrm{X}$ & & & 9 \\
\hline Chou et al. ${ }^{[8]}$ & 2004 & Cohort & 13 & $\mathrm{X}$ & & $\mathrm{X}$ & & 7 \\
\hline Göğüş et al. ${ }^{[20]}$ & 2004 & Cohort & 6 & $\mathrm{X}$ & & $\mathrm{X}$ & & 6 \\
\hline Al-Meshaan et al. ${ }^{[15]}$ & 2008 & Cohort & 9 & $X$ & & $\mathrm{X}$ & & 5 \\
\hline Aravantinos et al..$^{[13]}$ & 2008 & Cohort & 7 & $\mathrm{X}$ & & $\mathrm{X}$ & & 8 \\
\hline Tiwari et al. ${ }^{[17]}$ & 2011 & Cohort & 24 & $X$ & $\mathrm{X}$ & & $\mathrm{X}$ & 8 \\
\hline Wen et al. ${ }^{[19]}$ & 2012 & case series & 12 & $X$ & & $\mathrm{X}$ & $X$ & 7 \\
\hline Jang et al. ${ }^{[4]}$ & 2012 & Cohort & 52 & $X$ & & $\mathrm{X}$ & $X$ & 7 \\
\hline Lee et al. ${ }^{[14]}$ & 2015 & Cohort & 8 & $\mathrm{X}$ & & $\mathrm{X}$ & $\mathrm{X}$ & 5 \\
\hline Oshinomi et al. ${ }^{[11]}$ & 2018 & Cohort & 18 & $X$ & & $\mathrm{X}$ & & 9 \\
\hline Bhagat et al. ${ }^{[18]}$ & 2008 & Cohort & 48 & $\mathrm{X}$ & & $\mathrm{X}$ & $\mathrm{X}$ & 8 \\
\hline
\end{tabular}

AB: antibiotics; NOC: Newcastle-Ottawa scale 